\title{
New Interpretation of Extracurricular Activities via Social Networking Sites: A Case Study of Artificial Intelligence Learning at a Secondary School in Hong Kong
}

\author{
Tsz Kit Ng \\ Correspondence: Tsz Kit Ng, Faculty of Education, The University of Hong Kong, Pokfulam Road, Hong Kong. \\ Received: November 5, 2020 \\ Accepted: November 29, 2020 \\ Online Published: December 14, 2020 \\ doi:10.11114/jets.v9i1.5105 \\ URL: https://doi.org/10.11114/jets.v9i1.5105
}

\begin{abstract}
During the COVID-19 pandemic, attending after-school activities now becomes a luxury to students, which used to establish interests, friendships and social networks in an informal setting. Students lost contact with peers and teachers and were forced to attend blended courses at home, which may constitute threats to their non-academic issues, especially social needs and mental health of the most vulnerable students. This article overviews a new interpretation of extracurricular activities (ECAs) to teach artificial intelligence (AI) via a social networking site (SNS) among junior secondary school students in Hong Kong. A three-stage action research with the use of semi-structured interviews, motivational surveys and lesson observation was conducted. Based on how students perceived such pedagogical changes, the teachers employed various strategies to transform the "after-school" activities online. The investigation presented the planning processes on how to transform the informal learning activities to an online mode via SNSs that can reach the roles of ECAs in schooling. Our study indicated that meaningful activities rely on teachers' leading role to build a collaborative social media environment in order to facilitate social engagement among students.
\end{abstract}

Keywords: COVID-19, artificial intelligence learning, extracurricular activities, social media, gamification

\section{Introduction}

As the dangerous pandemic COVID-19 spreads globally, according to United Nations statistics, by March 18 2020, 107 countries around the world temporarily closed universities, secondary and primary institutes for an indefinite period of time due to the high risks of contagion in densely populated areas, consequently affecting 862 million students, roughly half the global student population (Viner et al., 2020). In Hong Kong, school classes have been suspended amid the COVID-19 pandemic since the end of Lunar New Year on February 3 in Hong Kong, one of the first few cities where the coronavirus outbreak was first reported. Educators quickly developed a diversified mode of learning to support students to learn at home during class suspension according to their school-based situations and students' needs during the crisis ( $\mathrm{Ng}$ et al., 2020; Education Bureau, 2020a).

Due to unprecedented "institutional deschooling" amid the COVID-19, educators and psychologists are concerned about the psycho-social consequences of students' social distancing which may adversely affect youth development (Fegert et al., 2020; Seçer, 2020). During the class suspension, students lost contact with peers and teachers and were confined at home to attend blended courses. All extracurricular activities (ECAs) were cancelled at schools which may constitute threats to academic disengagement and emotional health of students. This is supported by scholars who have found a linkage between participation in structured leisure activities to positive youth development and association of ECA involvement with both academic and risky behavior outcomes during youth adulthood (e.g. Eccles. 2003; Morrissey \& Wener-Wilson, 2005; Blomfield \& Barber, 2010). Participants in most ECAs achieved better academic outcomes than non-participants after keeping social class, gender, and intellectual aptitude constant (Eccles, 2003). However, due to the COVID-19 pandemic, attending after-school activities now becomes a luxury to students, which used to build up confidence, friendships and social networks in an informal setting (Haripersad et al., 2020; Stein-Zamir et al., 2020). Thanks to technological advancement, educators designed some flexible and meaningful ECAs to enrich students' learning and foster whole-person development with the use of social media tools and digital technologies in secondary schools (Şendurur et al., 2020; Nerantzi, 2020).

The current article proposes a new interpretation of ECAs through social networking sites (SNSs) for today's school educators, parents and students. This article seeks to serve a constructive purpose at a challenging moment in presenting a 
"lesson-learnt" to engage students to attend online ECAs. An action research approach was implemented in three stages to modify the artificial intelligence (AI) ECAs at a secondary school in Hong Kong to explore the use of SNSs on students' extra-curricular learning to enhance their motivation and social engagement in this digital era.

\subsection{Extracurricular Activities}

Extracurricular activities are defined in this study as informal learning opportunities provided by schools that do not fall into the realm of normal curriculum of schools (Eccles et al., 2003; Denault \& Guay, 2017). There are many organized and constructive leisure practices such as academic or community-based clubs, sports, student council, student newspaper, music, art, and drama, which are found in all levels of a school, to provide multiple learning opportunities for students to gain social, physical, and intellectual skills (Eccles \& Templeton, 2002; Denault \& Guay, 2017). A vast amount of research has shown evidence on the positive influences of ECAs towards students' development and academic affairs. Constructive and structured activities are a positive use of the adolescents' time because ECAs provide diversified informal learning opportunities (Barber et al., 2005; Eccles et al., 2003):

(a) to develop students social, physical and intellectual skills, and improve their academic performance;

(b) to contribute to the well-being and a sense of belonging as a member of one's community;

(c) to motivate students' active participation and self-autonomy associated with school attendance;

(d) to establish supportive social networks of peers and teachers in a positive school environment; and

(e) to build students' civic skills and practical abilities to deal with challenges.

\subsection{Student Engagement Model}

The function of ECA in schools can be explained by an alternative theoretical perspective proposed by Willms, Friesen and Milton's (2009, p.7) student engagement model, which is defined as "the extent to which students identify with and value schooling outcomes, have a sense of belonging at school, participate in academic and non-academic activities, strive to meet the requirements of schooling, and make a serious personal investment in learning." Based on this model, social engagement, especially in informal learning settings, is one of the three pillars to build a meaningful and well-rounded school life for K-12 learners. These non-academic activities such as school teams, clubs, student council, or school-wide campaigns are shown to have (a) positive student-teacher relationships, (b) friendships, (c) social networks, (d) sense of belonging, (e) self-confidence for student development, and (f) enjoyment of school. These elements played important roles to enhance students' whole-person development (Willms, Friesen \& Milton, 2009, p.7).

Based on these two perspectives, ECAs play a prominent role in informal learning opportunities to lead students a well-rounded psycho-social school life. However, when face-to-face classroom teaching became not possible during the COVID-19 pandemic, many non-academic activities tend to be cancelled or suspended. This makes the need for educators to move part of informal/ extracurricular activities online through collaborative learning tools such as SNSs.

\subsection{Social Networking Sites and Informal Online Learning}

With the rise of Web 2.0, SNSs have been widely used for collaboration and communication (Chu, 2017; Ellison, Steinfield, \& Lampe, 2007). Facebook is a popular SNS that is not only for developing interpersonal relationships and interaction but also for learning (Chu, 2017; Ellison, Steinfield, \& Lampe, 2007). Social media tools have diverse features which enable the sharing of articles, images, audio and videos (Hazari, North \& Moreland, 2009; Al-Bahrani, Patel \& Sheridan, 2015). Recent studies suggested that many schools are increasingly integrating SNSs as informal learning tools outside of school these years. Greenhow and Askari (2017) proposed SNSs as a form of information and communication technology with the following socio-technical features for informal learning (Ellison \& boyd, 2013, p. 7):

(a) identifiable profiles that consist of student-supplied content;

(b) internal or external display of social connections that can be traversed by other classmates; and

(c) content sharing features that allow students to create and interact with student-generated content based on classmates' connections on the SNSs.

Among the studies, researchers focused on how students use SNSs in informal online learning environments to facilitate social support and collaboration among students, and encourage self-directed and free-choice learning as well as construct a sense of online community and digital identity.

Facilitating social support and collaboration: Social network systems facilitate students' expression of their views through a robust social experience on a web-based platform which garnered students' interest and appeal, i.e. a facebook-like user experience (Mcloughlin \& Lee, 2010). Such technology creates a collaborative environment for teachers and students to socially connect with each other to share viewpoints, create products and receive timely feedback (Dron \& Anderson, 2014). For instance, Erjavec (2013), in a study of 60 primary students, used Facebook as an online 
learning environment to seek social support in handling school-related stress, organize group activities and share creative work that facilitates peer-alumni connections to help students' school-life transitions. In this sense, SNSs can enhance social capital development as an enrichment to formal education. In another study of 607 high school students from low-income families, Greenhow, Burton and Robelia (2011) conducted a regression analysis to find a positive relationship between intensity of online SNSs use, social capital and psychological well-being. It was found that the students can build bonding capital (i.e., connection with close family members and friends) and bridging capital (i.e., connection with knowledge and experience). In addition, blogs could be an effective platform for managing students' sharing of their internship learning experiences (Chu et al. 2012).

This article proposed Edmodo as the online learning environment to engage junior secondary students to learn AI in an informal context. Edmodo is a private educationally oriented SNS that has an interface that looks similar to Facebook for students to build learning networks to connect with teachers and classmates (Balasubramanian, Jaykumar \& Fukey, 2014). It allows learners to collaborate, communicate, share viewpoints, access homework and view grades (2014). Compared to other SNS like Facebook and Linkedin, Edmodo's inbuilt assessment functions are also deemed helpful to engage students in e-quiz, assignment, polling and students' profiles which have the potential to build peer support and social network within a school (Balasubramanian, Jaykumar \& Fukey, 2014). Learners have reported substantial learning benefits in terms of active participation in online activities, features in submitting tasks as well as ease to access reference materials and increase in student motivation (Enriquez, 2014). Although Edmodo can facilitate students' engagement cognitively in classroom learning, educators need to pay attention to some technical issues on the use of Edmodo such as bandwidth, confusion in using Edmodo, incompatibility of smartphone applications as well as students' lack responsibilities of learning. (Purnawarman, Susilawati \& Sundayana, 2016).

Encouraging self-directed and free-choice learning: Social networking sites offer students a sense of freedom to participate in the self-directed online activities. Yang, Crook and O'Malley (2014) examined how the SNSs are used to facilitate an after-school language activity in which educators encourage students to post on the extra-curricular 'community of inquiry' and promote a sense of freedom to practise Mandarin in an informal environment. In the US, Robelia, Greenhow and Burton (2011) investigated that Facebook applications can improve students' environmental knowledge and responsible behaviours by offering free-choice learning in an informal platform. Petreson (2012) emphasized the role of social connection in an informal online environment to socially interact around the digital learning episodes such as meaningful videos, games and simulations. Social network systems represent a partial decentralization of the management of learning, thus strengthening the association between learners and clustering learning material into categories from teachers to the learners themselves (Downs, 2010). These results demonstrated that like-minded students who have similar interests can participate in free-choice activities in an online community of SNSs.

Building a sense of community and digital identity: Unlike content management systems, students have more opportunities to be actively involved in personalization with the default features of the systems, thus potentially building a sense of online presence, community, digital identity construction, and interactive discussions (Dron \& Anderson, 2009; Greenhow, 2011; Lee \& Mclouglin, 2010). Social media tools can provide environments within which people can perform whatever identity they choose. Students can develop different identities through "dynamic and shifting constructions" through online profiles in SNSs (Coiro et al., 2008, p.526). The creation of these online profiles within social networks impacts directly on how students perform and reinforce their identities (Steinkuhler, 2008). In the profiles, students' identities are often associated with specific domains of extra-curricular participation such as sports, music band, student council, programming courses and volunteer services. Students build up self-confidence and identities through participating in activities that they think they can master and are familiar with (Dron \& Anderson, 2009; Greenhow, 2011; Lee \& Mclouglin, 2010). As such, online extracurricular activities via SNSs can encourage students to construct their own digital identities and build a sense of "community of inquiry" to connect with other participants.

To summarize, social networking sites demonstrate the features to support social engagement in extracurricular activities. The connection between SNSs, ECAs and social engagement can be conceptualized in three key dimensions, which form the analytic framework of this study (see Table 1). 
Table 1. The tri-relationship between extracurricular activities, social engagement and social networking sites

\begin{tabular}{l|l|l}
\hline Extracurricular Activities & Social Engagement & Social Networking Sites \\
\hline $\begin{array}{l}\text { Establishing supportive social } \\
\text { networks of peers and teachers in a } \\
\text { positive school environment. }\end{array}$ & $\begin{array}{l}\text { Providing positive relationships } \\
\text { with peers and teachers, } \\
\text { friendships, and social networks. }\end{array}$ & $\begin{array}{l}\text { Facilitating social support and } \\
\text { collaboration }\end{array}$ \\
\hline $\begin{array}{l}\text { Enjoyment of school. Motivating } \\
\text { students' active participation. }\end{array}$ & Enjoyment of school and learning. & $\begin{array}{l}\text { Encouraging self-directed and } \\
\text { free-choice learning. }\end{array}$ \\
\hline $\begin{array}{l}\text { Contribution to one's well-being } \\
\text { and sense of belonging in a } \\
\text { community. }\end{array}$ & $\begin{array}{l}\text { Sense of belonging, community, } \\
\text { identity construction and } \\
\text { self-confidence. }\end{array}$ & $\begin{array}{l}\text { Building a sense of community } \\
\text { and digital identity. }\end{array}$ \\
\hline
\end{tabular}

\section{Research Purpose and Questions}

This action research was motivated by the practical problems faced by the author in his teaching practice at a secondary school in Hong Kong. Before the COVID-19 pandemic, the cost of participating in ECAs such as technology and instrumental music, may be costly for some students from low-socioeconomic backgrounds to join these activities. Second, some parents tend to reduce the amount of face-to-face after-school activities for their students due to the heavy academic emphasis and examination-oriented culture in Hong Kong. During the class suspension, all after-school activities are cancelled, and students are encouraged to maintain social distance to minimize interactions with classmates. However, prior studies emphasised the prominent roles of ECAs in schools that attending schools is not merely about learning academic subjects such as language, math and science, but also about developing social skills, interests, relationships with classmates and social interactions (Eccles. 2003; Morrissey \& Wener-Wilson, 2005). The author observed that some students are so demotivated that they began to skip homework and online classes. As such, he designed an online learning community to learn AI via Edmodo to make learning at home interesting. Therefore, the overarching research question was: how do students perceive online ECAs as an alternative to meet their cognitive and social needs via a social networking site? Two research questions are formulated specifically:

RQ1. How do students perceive the new interpretation of online extracurricular activities via social networking sites to learn artificial intelligence?

RQ2a. How do educators change to meet students' needs to socially engage them to learn artificial intelligence?

RQ2b. How do educators change to meet students' needs to cognitively engage them to learn artificial intelligence?

\section{Methods}

Focusing on the practical problems, an action research was conducted with the use of a Motivated Strategies for Learning Questionnaire (MSLQ), semi-structured interviews and online lesson observation at a secondary school in Hong Kong.

Following Susman (1983), action research allowed the researcher to observe, analyse and interpret the student learning in the "Artificial Intelligence 101 (AI 101)" online community in our study. Action research is a naturalistic inquiry process based on participants' feedback and reflection which encourages educators to observe, analyse and interpret student learning for instructional design and decision-making (Stringer, 2008). It aims to solve practical issues by implementing and evaluating actions iteratively in a real context in four steps: problem definition, action design, action implementation, assessment and reflection (Avison, Baskerville \& Myers, 2001; Creswell, 2014). Working in the places where their colleagues work, naturalistic researchers illustrate narrative case studies on observational data, interviews, and other sources of descriptive (e.g. emails, school documents, forum dialogues) to create rich descriptions and interpretations of social phenomena (Armstrong, 2012). Instead of "manipulating outcomes as a priori" (Bowen, 2008), we focused on the self-experience, innate feelings and actions of the informants in real natural settings and assembled with the empirical data and the theoretical perspectives in order to explore the assemblage of schools to face their learning and teaching challenges. The results can help us look into how teachers make an abrupt move to online learning and teaching after the Hong Kong government's announcement of class suspension. By providing effective eLearning practices that emerged in our phenomenon, we hope to offer timely support to educators around the world to help them achieve "teaching as usual" during the COVID-19 crisis.

\subsection{Action Design and Implementation}

To solve the recent practical issues, the researcher proposed the use of Edmodo as an alternative to conducting ECAs to 
overcome the funding challenge and academic pressure in normal school days and reduce school-related delinquencies such as skipping classes, schoolwork quality, as well as social distancing during class suspension. Three rounds of action were conducted, as shown in Table 2. In the first round, the researcher prepared six meaningful videos, some discussion questions, e-quizzes and polling activities for students to learn interesting concepts about AI at Edmodo on a free-choice and self-directed basis. Problems were identified after the implementation in the previous round such as inactive participation and collaboration at Edmodo. As such, changes were made in the next stages to improve these issues. Details about how to improve the implementation of online ECA will be discussed later in the data analysis and result sections.

Table 2. Action implementation in three stages in an online interest community at Edmodo

\begin{tabular}{l|l|l}
\hline Stages & Problems/ Needs & Actions \\
\hline 1 & $\begin{array}{l}\text { Social distancing, academic } \\
\text { pressure, financial challenges, } \\
\text { time flexibility }\end{array}$ & $\begin{array}{l}\text { Teachers created online activities such as videos, discussion } \\
\text { forum, polling, e-quizzes in an online community at Edmodo }\end{array}$ \\
\hline 2 & $\begin{array}{l}\text { Inactive participation and } \\
\text { collaboration }\end{array}$ & $\begin{array}{l}\text { Teachers prepare some discussion questions and games to } \\
\text { encourage students' engagement, discussion and sharing. }\end{array}$ \\
\hline 3 & $\begin{array}{l}\text { Facilitate students' face-to-face } \\
\text { interaction. }\end{array}$ & $\begin{array}{l}\text { Teachers gather interested students to attend web conference } \\
\text { sessions to further discuss based on the online materials. }\end{array}$ \\
\hline
\end{tabular}

3.2 Participants

This study recruited voluntary students who are interested in learning AI at a secondary school in which one-fourth of the students come from low-income families in Hong Kong. In this school, students review that time, technical and financial constraints usually discourage them from joining after-school activities. During the class suspension, many students felt bored and isolated. With the students' consent, 60 junior form students were invited in three rounds of online activity at Edmodo. Four technology teachers at this school offered help in online activities to students.

\section{Instructions and data collection}

Both quantitative and qualitative data were collected to provide a thorough understanding of the research topic (Creswell et al., 2004). To evaluate the student perception, four sources of data were collected, consisting of:

- Motivational Strategies Learning Questionnaire (MSLQ)

- Semi-structured interviews and self-reports

- Lesson observations

- Online dialogue at Edmodo

The 33-item questionnaire was based on the revised Chinese version of Motivated Strategies for Learning Questionnaire (MSLQ-RCV) (Lee, Yin \& Zhang, 2010) and included three domains: self-efficacy, intrinsic motivation and self-regulation. It was measured on a five-point Likert scale, ranging from strongly agree to strongly disagree. The questionnaire also raised six questions about the user experience of specific features of the SNSs. For example, the students were asked to rate the "user experience", such as "I found Edmodo allows me to construct a personal identity like Facebook." or "I can share comments, ideas and my work (e.g. AI models) at Edmodo." Cronbach's alpha coefficients of internal consistency were measured to estimate the reliability of the instruments. All items in the questionnaire were considered highly reliable $(>0.90)$. Furthermore, some students agreed to further participate in semi-structured interviews and self-reports through webinars or in written formats. One of the authors of this study collected these data from both teachers and students.

\section{Data analysis and results}

The results of data analysis in the three rounds of activities are presented to improve the observed problems to improve the implementation of online ECAs in each stage.

\section{Action implementation in the first round in mid-February}

At the beginning of the first round, the students were reminded that the participation in the activity and research was not mandatory. Three computer teachers (including the author) sent invitation emails to encourage students to participate in the activity. The action of SNSs targeted 30 junior form students who could only attend online courses during the 
COVID-19 pandemic. In the study, they attended an online interest group via Edmodo. As most students viewed Edmodo as a new learning tool, they did not have any clues about what they should do with the SNS. We first asked students for their perceptions towards ECAs with the use of Edmodo after two weeks of action implementation. In the first stage, after the researcher had promoted the interest groups about AI through school emails, around 30 voluntary students felt interested in the activity. Due to inactive participation, there were only 10 boys and 2 girls who tended to be more actively engaged in some online activities such as polling and e-quizzes. We presented the coding of their responses through self-reflection and interviews in Table 2. All students believed that Edmodo helped divert them from boredom during the class suspension and learning AI was interesting.

Table 3. Students responses in the first stage

\begin{tabular}{l|l|}
\hline Questions & Students responses \\
\hline Why did you join this activity? & $\begin{array}{l}\text { Time offered, as COVID-19 makes me bored; the topic is interesting/ being } \\
\text { a technology enthusiast; Teacher recommendation. }\end{array}$ \\
\hline $\begin{array}{l}\text { What aspects were most useful } \\
\text { or valuable? }\end{array}$ & $\begin{array}{l}\text { Learn new knowledge about AI and machine learning; Interactive elements } \\
\text { such as comment and online tasks; Socialize with other participants. }\end{array}$ \\
\hline $\begin{array}{l}\text { How would you improve this } \\
\text { course? }\end{array}$ & $\begin{array}{l}\text { Good enough; Introduce more complex mathematics and computer } \\
\text { algorithms related to AI; More teachers'guidance as some contents are too } \\
\text { difficult. }\end{array}$ \\
\hline $\begin{array}{l}\text { What features did you like in } \\
\text { the Edmodo? }\end{array}$ & $\begin{array}{l}\text { Interact in the sub-groups (group facilitation), Share comments like } \\
\text { Facebook; Lesson materials are structured and tidy; Have interactive } \\
\text { features of polling, e-quiz and assessment; Have interactive Facebook-like } \\
\text { features (e.g. give likes, leave comments). }\end{array}$ \\
\hline
\end{tabular}

It is observed that the participation rate is low. Most of the participants merely joined the online interest groups but did not engage in commenting, polling, discussion and e-quiz activities. Only the technology enthusiasts could discuss and complete some online activities at their own pace. Among 12 interviewees, six students felt bored during the class suspension and three reported that AI was interesting. The researcher further asked the students how to improve the platform so as to attract more students to join. The technology student enthusiasts in this study suggested more challenging tasks related to mathematics and computer algorithms related to AI; whereas some low-performers think the content is too in-depth for junior students and suggested that appropriate guidance and assistance were necessary at Edmodo. In addition, the researchers want to know which learning elements of the Edmodo should be reinforced. Some students reflected that the interface of Edmodo looks like the one of Facebook in which lesson materials are structured and interactive. Moreover, some students commented that the online community offers students free choices and its functions are useful for them to share viewpoints and work among technology enthusiasts despite the fact that there has not been much active participation yet.

\section{Action implementation in the second round in mid-March}

Based on the reflection and challenges found in the first round, some changes were made to motivate student learning. First, all four IT teachers in the school were involved in posting comments and some learning elements like gamifications and digital certificates were introduced to motivate students to engage in the interest group. First, an AI model trainer was adopted as the gamification tool. Students can train a classification model to distinguish between red flowers and green leaves; some of them shared their work after they completed. They became more active in expressing themselves by sharing ideas and polling on the platform. Second, after co-planning, the teachers created an identity at Edmodo and shared some interesting resources about AI learning in the platform. Students gave "likes" as they experienced on Facebook. Teachers left some comments to guide students on how to use the materials on the platform. Third, after students successfully completed all the online activities, they would receive a digital certificate. The Facebook-like features were useful for teachers to share viewpoints, and encourage student interaction and learning, as shown in the Data extract one.

Data extract 1: Sharing useful resources of AI learning (21 March 2020)

Mr. Ng shared some AI modelling gamifications such as https://code.org/oceans. "Computer science is about so much more than coding! Learn about artificial intelligence (AI), machine learning, training data, 
and bias, while exploring ethical issues and how AI can be used to address some world problems. Enjoy the AI for Oceans activity where you are training real machine learning models!” (Mr. Ng, Edmodo post, 2020).

Three students shared their designed AI model and gave "likes" to each other's posts.

\section{Quantitative results}

During the second-round activity, 33 registered students became more active and engaged in online activities such as discussion, polling and e-quiz. All of them reviewed the Edmodo community after one month of implementation in mid-April. Among the participants, 12 students spent more than two hours per week on average at Edmodo. Moreover, 11 of them spent around an hour and the rest of the ten participants used less than an hour per week. Based on the coding of student responses during interviews in the first stage, we ask three major reasons for students to engage in AI learning at Edmodo: leisure purpose or free-choice learning $(\mathrm{n}=18)$, AI as an interesting topic $(\mathrm{n}=5)$, and teachers' recommendation $(n=2)$. This study showed that the online ECAs offered students enjoyment of learning and helped divert them from boredom during the class suspension. Concerning the learning experience of Edmodo, students reflected that the platform consists of facebook-like interactive features such as polling, like, personal identity, and commenting, as well as inbuilt interactive functions such as e-quiz and assessment $(\mathrm{n}=19)$. In addition, the platform offers a structured content management $(n=3)$ and a digital certificate $(n=1)$. The rest of the students did not comment on the reasons for participating in the platform nor sharing their learning experience of Edmodo.

In the second stage, 33 participants completed the MSLQ on a five-point Likert scale and there are 28 valid data. As shown in table three, students have high intrinsic motivation, self-efficacy and self-regulation during the online "after-school" activity. They gave a high rating for intrinsic motivation $(M=3.52, S D=0.675)$, self-efficacy $(M=3.31$, $S D=0.556)$, self-regulation $(M=3.30, S D=0.481)$. On the other hand, students gave a high rating for Edmodo features items $(M=3.11, S D=0.703)$, such as identity construction, interactive features polling, assessment tools, e-quiz, commenting, digital certificates and structuralized content management. As shown in the study, these elements facilitate students to support and collaborate with other participants in an online community.

\section{Qualitative results}

Inactive participation and collaboration were two of the major concerns in the first round based on students' active rate of participation and their learning outcome at Edmodo. Students thought that the online "after-school" activity can help divert them from boredom and enrich their learning with interesting knowledge. Students reflect that they can create their personal account to give "likes" and leave comments, share their ideas through polling and comments, and get a certificate after completing the e-quiz. Some activities are shown in the Data extract two.

Data extract 2: Three online activities in AI learning interest group (21 March 2020)

Polling I think facial recognition is the most widely used AI technology in daily life (63\%).

E-quiz (image)

Discussion questions (The comments are translated into English):

Teacher Mr. T: Based on daily life observation, try to give some examples of the application of artificial intelligence, and point out which application it belongs to.

Student C: Face, voice and fingerprint recognition are [examples of applications] to "unlock" a smartphone.

Teacher Mr. T: Yes, so do you think that [these applications] of artificial intelligence in smartphones are good enough?

Student C: Like fingerprint unlocking, if there is some water or dirt on the fingertips, it [may be] difficult to unlock [the smartphones]. But under what circumstances, the face recognition [still cannot be used to] unlock a smartphone, for example, "without wearing a glass". [So we need to improve the inputting methods by using different kinds of recognitions].

Teacher Mr. T: Good point! [Give a like]

Data extract 3: Conservation in AI learning interest group (21 March 2020)

Student M: I have made an AI model trainer. Please take a look! It can distinguish between airplanes, buses and taxis.

Teacher Mr. Ng: Good! Can you share with me your dataset?

Student M: I used 11 airplanes photos, 10 ships, 12 taxis and 12 buses. [Attached with the AI model trainers with raw dataset.]

The author later met some participants in a web conference to know how they perceived the online after-school activities 
at Edmodo. A student Peter felt that there was little difference in the enjoyment of learning and students' interaction between such online informal learning and traditional ECAs, and commented:

"I use Instagram and Facebook [in my leisure time] every day. I spend [on the community platform] as long as I like to study the [online] materials. I can give feedback on other classmates and share my viewpoints. [On the whole,] I feel enjoyable in this kind of [informal] learning."

Another student who seldom attended ECA at school due to parental control stated:

"My parents always feel worried about me that I can't strike a balance between ECA and academics. The materials are educational; my parents will certainly allow me to attend. Also, I can choose which parts to learn on the platform freely."

Johnson, a student who had received school textbook assistance claimed:

"Budget is one of my concerns when I choose after-school activities. These kinds of [online] activities could enrich my learning exposure at a zero cost."

An instructor reported that the informal activities are meaningful to engage the bored students during class suspension, and reviewed:

"The platform provides flexibility and different levels of difficulty which suit Secondary one to three students. For the higher achiever, they can choose to learn more advanced topics at Edmodo. In other words, They can make good use of the [spare] time during class suspension to learn new knowledge."

Therefore, in the next session, the researcher provided some web conferencing sessions for students and shared more interesting artefacts at Edmodo. This online ECA approach was not only used in the days of class suspension. Many students, especially boys, enjoy using new technologies. On one hand, instead of playing computer games after completing assignments in normal school days, this online approach of informal activities can allow students to make good use of their spare time to enrich their learning at home. On the other hand, the free-of-charge courses can address the problem of students' financial and academic issues. Based on the quantitative and qualitative results, this interpretation of online informal learning is positive; however, some students requested to have some web conferencing sessions to discuss some difficult and interesting concepts mentioned in the materials with teachers and other participants.

\section{Action implementation in the third round in mid-May}

To explore the differences in perceptions between SNS and the synchronous mode, the researcher invited 33 junior form students to four sessions of face-to-face online meetings and online activities at Edmodo in stage three. With the support of synchronous technologies, the instructors gave online meetings via Google Meet, instructors engaged students in some interesting issues and discussed some difficult concepts about AI learning at Edmodo. For example, students asked the instructor to clarify the difference between two algorithms, k-nearest neighbors and convolutional neural networks, and how to traverse the nodes in a tree diagram. All these concepts are not covered in the secondary school technology curriculum.

Similarly, the participants completed the MSLQ. An Independent sample $t$ test is used to compare the difference between the second and third rounds. As shown in table 4, students obtain a slightly lower intrinsic motivation, self-efficacy and self-regulation. They gave a rating for intrinsic motivation $(M=3.39, S D=0.767)$, self-efficacy $(M=3.24, S D=0.527)$, self-regulation $(M=3.03, S D=0.352)$. One limitation is that the sample size of the SNS and synchronous group is small. An independent sample $t$ test with a significant level of 0.05 was used to reveal the difference between the second and third round. No significant difference was found in score, self-efficacy, intrinsic motivation, home anxiety and user experience at Edmodo of students. However, there was a significant difference in self-regulation between the second and third rounds $(\mathrm{t}=2.507, \mathrm{p}=0.018)$. The self-regulation for students who attend face-to-face Google Meet sessions was 3.03 lower than that of the Edmodo group. One reason is that students tend to be more self-regulated if they choose to attend informal learning of Edmodo courses on a free-choice basis. 
Table 4. Group statistics of synchronous technology $(n=33)$

\begin{tabular}{l|c|c}
\multicolumn{1}{c|}{ Constructs } & Mean & SD \\
\hline Score & 9.36 & 3.277 \\
\hline Self-efficacy & 3.24 & 0.527 \\
\hline Intrinsic motivation & 3.39 & 0.767 \\
\hline Self-regulation & 3.03 & 0.352 \\
\hline User experience at Edmodo & 3.16 & 0.702 \\
\hline Home anxiety & 2.81 & 0.667 \\
\hline
\end{tabular}

Table 5. Self-regulation between Edmodo and Google Meet groups

\begin{tabular}{l|c|c|c|c|c}
\hline Groups & $\mathbf{N}$ & Mean & SD & $\mathbf{t}$ & $\mathbf{p}$ \\
\hline Edmodo & 28 & 3.30 & 0.481 & 2.507 & 0.015 \\
Google Meet & 33 & 3.03 & 0.352 & & \\
\hline $\mathrm{p}<0.05^{*}$ & & & & \\
\hline
\end{tabular}

Some interviews and self-reports were conducted with the students and instructors. The students proposed that this new interpretation of ECA was meaningful although students still prefer traditional after-school activities unless it is impossible due to various reasons. As discussed, financial and academic issues are reasons why students cannot attend the after-school activities. Another reason is that some students may have time clashes between two different ECAs such as attending tutorial classes and preparing for competitions. Such an online community with the support of Google Meet can encourage them to participate in the online collaborative activities in a social networking environment. In addition, some students claimed that teachers can lead and guide student discussion in the Google Meet with more collaborative and face-to-face interaction which is impossible at SNSs. An instructor, Mr. K, gave some feedback to our researcher that during the COVID-19 pandemic and commented:

"all after-school activities are cancelled even after the class resumes until further notice. It can be a luxury that schools can afford amid this time. We are not alone. [We are not the only school in Hong Kong that provides some informal online activities during class suspension.] Some teachers become YouTubers these days to make learning fun such as playing musical instruments, dancing or even making desserts with students through webinars and other learning management systems. It is believed that this kind of online activities can be resumed to enrich student learning especially to some busy students who seldom attend ECA or avoid social interaction."

\section{Conclusions and Recommendations}

As the focus of the study was not how the educators teach AI via SNSs in an informal setting, this article will mainly discuss how SNSs were used to reach the educational purposes of social engagement in ECAs. Based on the data analysis in the three phases, the results showed that the new interpretation of AI ECAs at Edmodo has a potential to offer students learning opportunities. This approach engages students in blended activities with the use of SNSs and other web-based tools. The participants gave positive responses towards the use of these digital technologies to learn AI through interaction and discussion at Edmodo. This case study demonstrated the tri-relationship of extracurricular activity, social networking sites and social engagement. First, the first-round results demonstrated the needs of students at the beginning of ECAs so that the author tried to incorporate more socially interactive features into the ECAs. It showed that they can effectively develop positive relationships among peers and teachers, created connections between classmates and developed their 
interests and enjoyment of AI learning via Edmodo. The motivational survey also showed that students can enjoy learning throughout the online informal activities. Third, students' interviews suggested that such blended learning experiences can effectively build "a sense of community" to learn AI at home in which students demonstrated to use various socio-technical features such as work-sharing, commenting, and polling within the SNS to interact in a decentralized learning manner.

However, there were few limitations in this study. The first limitation was derived from the exploratory nature of the action research and data collection in a real scenario of learning and teaching in such a rush time. No control group was used to compare the learning outcomes of the experimental group. Moreover, there might be teachers' effect in the synchronous sessions and technical issues were also concerns that potentially affected the effectiveness of using SNS to teach AI in an online extracurricular setting. For example, the teachers' characteristics and their online teaching strategies would make the experimental results different. It is recommended that future studies should be conducted to reduce these potential problems and further improve the effects of adopting other interesting activities, social media tools and learning artefacts in AI learning such as robotics and simulation tools. Overall, the study offers a "lesson-learnt" that K-12 educators today can continue to design and implement online ECAs to enrich student learning especially for those who cannot participate in after-school activities due to various reasons such as time constraints, costs and socioeconomic status.

\section{References}

Al-Bahrani, A., Patel, D., \& Sheridan, B. (2015). Engaging students using social media: The students' perspective. International Review of Economics Education, 19, 36-50. https://doi.org/10.1016/j.iree.2015.06.001

Al-Kathiri, F. (2015). Beyond the Classroom Walls: Edmodo in Saudi Secondary School EFL Instruction, Attitudes and Challenges. English Language Teaching, 8(1), 189-204. https://doi.org/10.5539/elt.v8n1p189

Armstrong, S. J., Cools, E., \& Sadler-Smith, E. (2012). Role of cognitive styles in business and management: Reviewing 40 years of research. International Journal of Management Reviews, 14(3), 238-262. https://doi.org/10.1111/j.1468-2370.2011.00315.x

Avison, D., Baskerville, R., \& Myers, M. (2001). Controlling action research projects. Information technology \& people. https://doi.org/10.1108/09593840110384762

Balasubramanian, K., Jaykumar, V., \& Fukey, L. N. (2014). A study on "Student preference towards the use of Edmodo as a learning platform to create a responsible learning environment". Procedia-Social and Behavioral Sciences, 144(1), 416-422. https://doi.org/10.1016/j.sbspro.2014.07.311

Barber, B. L., Stone, M. R., Hunt, J. E., \& Eccles, J. S. (2005). Benefits of activity participation: The roles of identity affirmation and peer group norm sharing. Organized activities as contexts of development: Extracurricular activities, after-school and community programs, 185-210.

Blomfield, C., \& Barber, B. (2010). Australian Adolescents' Extracurricular Activity Participation and Positive Development: Is the Relationship Mediated by Peer Attributes?. Australian Journal of Educational \& Developmental Psychology, 10, 114-128.

Bowen, G. A. (2008). Naturalistic inquiry and the saturation concept: a research note. Qualitative research, 8(1), 137-152. https://doi.org/10.1177/1468794107085301

Chu, S. K., Capio, C. M., van Aalst, J. C., \& Cheng, E. W. (2017). Evaluating the use of a social media tool for collaborative group writing of secondary school students in Hong Kong. Computers \& Education, 110, 170-180. https://doi.org/10.1016/j.compedu.2017.03.006

Chu, S. K., Chan, C. K., \& Tiwari, A. F. (2012). Using blogs to support learning during internship. Computers \& Education, 58(3), 989-1000. https://doi.org/10.1016/j.compedu.2011.08.027

Coiro, J., Knobel, M., Lankshear, C., \& Leu, D. J. (2008). Central issues in new literacies and new literacies research. Handbook of research on new literacies, 1-21.

Crawford, J., Butler-Henderson, K., Rudolph, J., Malkawi, B., Glowatz, M., Burton, R., \& Lam, S. (2020). COVID-19: 20 countries' higher education intra-period digital pedagogy responses. Journal of Applied Learning and Teaching, 3(1). https://doi.org/10.37074/jalt.2020.3.1.7

Creswell, J. W., Fetters, M. D., \& Ivankova, N. V. (2004). Designing a mixed methods study in primary care. The Annals of Family Medicine, 2(1), 7-12. https://doi.org/10.1370/afm.104

Denault, A. S., \& Guay, F. (2017). Motivation towards extracurricular activities and motivation at school: A test of the generalization effect hypothesis. Journal of Adolescence, 54, 94-103. 
https://doi.org/10.1016/j.adolescence.2016.11.013

Downes, S. (2010). New technology supporting informal learning. Journal of emerging technologies in web intelligence, 2(1), 27-33. https://doi.org/10.4304/jetwi.2.1.27-33

Dron, J., \& Anderson, T. (2014). Teaching crowds: Learning and social media. Athabasca University Press. https://doi.org/10.15215/aupress/9781927356807.01

Eccles, J. S., \& Templeton, J. (2002). Chapter 4: Extracurricular and other after-school activities for youth. Review of research in education, 26(1), 113-180. https://doi.org/10.3102/0091732X026001113

Eccles, J. S., Barber, B. L., Stone, M., \& Hunt, J. (2003). Extracurricular activities and adolescent development. Journal of social issues, 59(4), 865-889. https://doi.org/10.1046/j.0022-4537.2003.00095.x

Ellison, N. B., Steinfield, C., \& Lampe, C. (2007). The benefits of Facebook “friends:" Social capital and college students' use of online social network sites. Journal of computer-mediated communication, 12(4), 1143-1168. https://doi.org/10.1111/j.1083-6101.2007.00367.x

Enriquez, M. A. S. (2014, March). Students' Perceptions on the Effectiveness of the Use of Edmodo as a Supplementary Tool for Learning. In DLSU Research Congress (pp. 1-6).

Erjavec, K. (2013). Informal learning through Facebook among Slovenian pupils. Comunicar, 21(41), 117-126. https://doi.org/10.3916/C41-2013-11

Fegert, J. M., Vitiello, B., Plener, P. L., \& Clemens, V. (2020). Challenges and burden of the Coronavirus 2019 (COVID-19) pandemic for child and adolescent mental health: a narrative review to highlight clinical and research needs in the acute phase and the long return to normality. Child and adolescent psychiatry and mental health, 14, 1-11. https://doi.org/10.1186/s13034-020-00329-3

Greenhow, C. (2011). Youth, learning, and social media. Journal of Educational Computing Research, 45(2), 139-146. https://doi.org/10.2190/EC.45.2.a

Greenhow, C., \& Askari, E. (2017). Learning and teaching with social network sites: A decade of research in K-12 related education. Education and information technologies, 22(2), 623-645. https://doi.org/10.1007/s10639-015-9446-9

Haripersad, Y. V., Kannegiesser-Bailey, M., Morton, K., Skeldon, S., Shipton, N., Edwards, K., ... \& Martin, A. C. (2020). Outbreak of anorexia nervosa admissions during the COVID-19 pandemic. Archives of Disease in Childhood. https://doi.org/10.1136/archdischild-2020-319868

Hazari, S., North, A., \& Moreland, D. (2019). Investigating pedagogical value of wiki technology. Journal of Information Systems Education, 20(2), 8.

Holland, C., \& Muilenburg, L. (2011, March). Supporting student collaboration: Edmodo in the classroom. In Society for Information Technology \& Teacher Education International Conference (pp. 3232-3236). Association for the Advancement of Computing in Education (AACE).

Hong Kong Education Bureau (2020a, March). Using e-learning platforms in combination with flipped classroom strategy to support student learning at home. https://www.edb.gov.hk/en/edu-system/primary-secondary/applicableto-primary-secondary/it-in-edu/flipped.html

Lee, J. C. K., Yin, H., \& Zhang, Z. (2010). Adaptation and analysis of Motivated Strategies for Learning Questionnaire in the Chinese setting. International Journal of Testing, 10(2), 149-165. https://doi.org/10.1080/15305050903534670

Lee, M., \& McLoughlin, C. (2010). Beyond distance and time constraints: Applying social networking tools and Web 2.0 approaches in distance education. In Emerging technologies in distance education (pp. 61-87). Athabasca University Press.

McLoughlin, C., \& Lee, M. J. (2010). Personalised and self regulated learning in the Web 2.0 era: International exemplars of innovative pedagogy using social software. Australasian Journal of Educational Technology, 26(1). https://doi.org/10.14742/ajet.1100

Morrissey, K. M., \& Werner-Wilson, R. J. (2005). The relationship between out-of-school activities and positive youth development: An investigation of the influences of communities and family. Adolescence, 40(157).

Nerantzi, C. (2020). The use of peer instruction and flipped learning to support flexible blended learning during and after the COVID-19 Pandemic. International Journal of Management and Applied Research, 7(2), 184-195. https://doi.org/10.18646/2056.72.20-013

Ng, T. K., Reynolds, R., Chan, M. Y. H., Li, X. H., \& Chu, S. K. W. (2020). Business (Teaching) as Usual Amid the COVID-19 Pandemic: A Case Study of Online Teaching Practice in Hong Kong. Journal of Information Technology 
Education: Research, 19, 775-802. https://doi.org/10.28945/4620

Peterson, M. (2012). Learner interaction in a massively multiplayer online role playing game (MMORPG): A sociocultural discourse analysis. ReCALL, 24(03), 361-380. https://doi.org/10.1017/S0958344012000195

Purnawarman, P., Susilawati, S., \& Sundayana, W. (2016). The use of Edmodo in teaching writing in a blended learning setting. Indonesian Journal of Applied Linguistics, 5(2), 242-252. https://doi.org/10.17509/ijal.v5i2.1348

Quong, J., Snider, S. L., \& Early, J. (2018). Reducing transactional distance in online and blended courses through the use of a closed social media platform. Journal of Educational Technology Systems, 47(1), 79-100. https://doi.org/10.1177/0047239518766654

Robelia, B. A., Greenhow, C., \& Burton, L. (2011). Environmental learning in online social networks: Adopting environmentally responsible behaviors. Environmental Education Research, 17(4), 553-575. https://doi.org/10.1080/13504622.2011.565118

Seçer, İ., \& Ulaş, S. (2020). An Investigation of the Effect of COVID-19 on OCD in Youth in the Context of Emotional Reactivity, Experiential Avoidance, Depression and Anxiety. International Journal of Mental Health and Addiction, 1-14. https://doi.org/10.1007/s11469-020-00322-z

Şendurur, E., Bilgiç, H. G., \& Şendurur, P. (2019). Integrating formal and informal learning opportunities of technology in higher education. In Handbook of research on innovative digital practices to engage learners (pp. 379-400). IGI Global. https://doi.org/10.4018/978-1-5225-9438-3.ch020

Steinkuehler, C. A. (2008). Cognition and literacy in massively multiplayer online games. Handbook of research on new literacies, 611-634.

Stein-Zamir, C., Abramson, N., Shoob, H., Libal, E., Bitan, M., Cardash, T., ... \& Miskin, I. (2020). A large COVID-19 outbreak in a high school 10 days after schools' reopening, Israel, May 2020. Eurosurveillance, $25(29), 2001352$. https://doi.org/10.2807/1560-7917.ES.2020.25.29.2001352

Stringer, E. T. (2008). Action research in education. Upper Saddle River, NJ: Pearson Prentice Hall.

Susman, G. I. (1983). Action research: a sociotechnical systems perspective. Beyond method: Strategies for social research, 95,113 .

Thongmak, M. (2013). Social network system in classroom: Antecedents of edmodoC adoption. Journal of E-learning and Higher Education, 2013(1), 1-15. https://doi.org/10.5171/2013.657749

Viner, R. M., Russell, S. J., Croker, H., Packer, J., Ward, J., Stansfield, C., Mytton, O., Bonell, C., \& Booy, R. (2020). School closure and management practices during coronavirus outbreaks including COVID-19: A rapid systematic review. The Lancet Child \& Adolescent Health. https://doi.org/10.2139/ssrn.3556648

Willms, J. D., Friesen, S., \& Milton, P. (2009). What Did You Do in School Today? Transforming Classrooms through Social, Academic, and Intellectual Engagement. (First National Report).

Yang, Y., Crook, C., \& O'Malley, C. (2014). Can a social networking site support afterschool group learning of Mandarin?. Learning, Media and Technology, 39(3), 267-282. https://doi.org/10.1080/17439884.2013.839564

\section{Copyrights}

Copyright for this article is retained by the author(s), with first publication rights granted to the journal.

This is an open-access article distributed under the terms and conditions of the Creative Commons Attribution license which permits unrestricted use, distribution, and reproduction in any medium, provided the original work is properly cited. 